\title{
Tru-Cut Biopsy Needle
}

National Cancer Institute

\section{Source}

National Cancer Institute. Tru-Cut Biopsy Needle. NCI Thesaurus. Code C128664.

A proprietary biopsy needle designed for manual capture of high-quality tissue samples

with minimal trauma to the patient. 